\title{
Candidosis on oral lichen planus
}

\author{
Kus Harijanti and Mintarsih \\ Department of Oral Medicine \\ Faculty of Dentistry Airlangga University \\ Surabaya - Indonesia
}

\begin{abstract}
ABTRACT
Oral lichen planus $(O L P)$ is a chronic inflammatory disease of the oral mucous membrane which is characterized by unpredictable exacerbation and remission. The pathognomonic of oral features of OLP are hyperkeratotic striation surrounded white patches of mucosal erythema are called Wickham's Striae. Chronic inflammation or epithelial damage of the mucous membrane often followed by candidosis as secondary infection. Candida species are commensal microorganism, its population in oral cavity reach $70 \%$ of the oral microorganism. It is harmless, but it could become opportunistic pathogen when the condition of oral environment support, i.e. decrease of oral immune response or the oral microorganism ecosystem change. This purpose of the paper was to report the case of a female patient (49 years old) who came to the clinic of Oral Medicine Faculty of Dentistry Airlangga University Surabaya with clinical and mycological evidence of thrush (Oral acute pseudomembrane candidosis). The patient not only suffered thrush, but also chronic cervicitis vaginalis. So the patient also consumed the antibiotic which was given by gynecologist. The used of the antibiotic for chronic servicitis vaginalis was the contrary treatment of oral thrush, after treated with nystatin oral suspention, clinical examination showed clearly hyperkeratotic lesion (Wickham's striae), and hystopathological test result showed that it was OLP. The chronic oral inflammation and epithelial damage $(O L P)$ or antibiotic consumption could inhibited the candidosis treatment. The case report suggested that the first treatment should be given antimicotic if the mycological test of candidosis showed positive result.
\end{abstract}

Key words: oral lichen planus, thrush

Correspondence: Kus Harijanti, c/o: Bagian Oral Medicine, Fakultas Kedokteran Gigi Universitas Airlangga. Jln. Mayjend. Prof. Dr. Moestopo No. 47 Surabaya 60132, Indonesia.

\section{INTRODUCTION}

Lichen planus (LP) is inflammatory disease that manifests on skin and oral mucous membrane and LP in oral mucous membrane is called oral lichen planus (OLP). ${ }^{1}$ The genitals are involved in as many as $25 \%$ of women with OLP, compared with only $2-4 \%$ of men with OLP. ${ }^{2}$ The ethiopathogenesis of OLP is still unknown, but recent studies revealed that cellular immune mechanisms might have a significant role. ${ }^{2-5}$ In many patients, the onset of OLP is insidious and the patients are unaware of their oral condition. In such instances, the referring medical or dental practitioner identifies the clinical changes in the oral mucosa. Some patients report a roughness on the lining of the mouth, sensitivity of the oral mucosa to hot/spicy foods or oral hygiene products. ${ }^{2}$ Oral lichen planus (OLP) could persist in years as a chronic disease, but it could often disappeared spontaneously. The incidence of OLP associated with emotional stress. ${ }^{1}$ It appears in the oral mucosa in various lesions, i.e. white striation (Wickham's striae), white papula, erythema (mucosal atrophy), erosions/ shallow ulcers or blisters. The predominant side of the lesion in oral mucosa are on the bilateral buccal mucosa, it also could be found in the other side of oral mucosa. ${ }^{6}$ Histological finding of OLP are densed bandlike lymphocytic infiltrate ( $\mathrm{T}$ cells) at interface between the epithelium and the connective tissues, focal areas of hyperkeratinized epithelium (which give rise to the clinically apparent Wickham's striae), and atrophic epithelium where the rete pegs may be shortened and pointed (as sawtooth rete pegs). ${ }^{7}$ Degeneration of the basal keratinocytes and disruption of the anchoring elements of the epithelium on basement membrane and basal keratinocyte (eg. hemidesmosomes, filaments, fibrils) weakened epithelial connective tissue interface. ${ }^{2}$

Candida albicans (C. albicans) are commensal organism, present in more than $70 \%$ of the population. ${ }^{2}$ It is harmless, but it could become opportunistic pathogen when the condition of oral environment support, i.e. decrease of oral immune response or the oral microorganism ecosystem change. Candidosis is an infection cause by candida, mainly $C$. albicans. Clinical features of oral candidosis could be divided into 4 types as follow: Acute pseudomembrane candidosis (thrush); acute atrophic candidosis; chronic atrophic candidosis and chronis hyperplastic candidosis. Oral candidosis has many predisposition factors for example treatment with broad spectrum antibiotics particularly high dose, prolonged administration of topical or systemic corticosteroids, and immunologic disorders or chronic inflammatory/damage on the oral mucous membrane. ${ }^{8}$ 
This case appeared to be a problem for dentists if they found oral candidosis (thrush), which clinically characterized milky white patch, and under the thrush could be a more serious problem as OLP. At the clinic of Oral Medicine Faculty of Dentistry Airlangga University Surabaya, only 10 cases of symptomatic OLP had been found since 1997 to 2002 . The patients complained of pain sensation and the oral mucosa was very sensitive to hot/spicy food. Duration of complaint was in the range of one to two years. ${ }^{9}$ Oral lichen planus (OLP) rarely found at clinic but the patients really suffered because the disease could not be totally recovered. The paper reported a case of OLP with thrush and chronic cervicitis vaginalis.

\section{CASE}

Visit 1: A 49-year-old Javanese female patient, was referred to clinic of Oral Medicine Faculty of Dentistry Airlangga University Surabaya by the dentist from Madiun. The complaint of patient was the presence of painful white-plaques bilateral buccal mucosa, sensitive of the spicy foods and difficult to open the mouth. She had those complaints for one year. For the last one month, the patient had more severe complaint than before. Afterward she went to a physician and was treated with topical-paste, but the lesions did not recover. Later, the patient was referred to a dentist. Firstly, the patient was treated with extract sanguine $5 \%+$ polidocanol $0.1 \%$ topically-gel 2 tubes @ 5 g. Since the patient still complaint of pain sensation, she was then treated with $0.1 \%$ triamcinolone acetonid in-orabase and tetracycline tablets. Few days later, the patient could open her mouth, but the pain and the lesions in the oral mucosa still exist. During the oral treatment, the patient also visited the oncologist since three months before the oral treatment, she experienced intercourse pain followed by post coital bleeding pervaginam. From the clinical examination revealed that general condition of the patient was not bad, but extra oral examination showed acute lymphadenitis on the right and left submandibular gland. No skin lesion was found. In intra oral appeared multiple thick-white-plaques on the left of buccal mucosa of 34, 35 and 36, which could not be scraped off. Its size was approximately $10 \times 20 \mathrm{~mm}$, painful, surrounded by erosion area (Figure 1). It also found on the right buccal mucosa. The pain sensation on the right side was not as severe as the pain on the left side. White-irregular patch and erythemathous base were found on attached gingiva of maxilla and mandibula (Figure 2). There were multiple ulcers on the mucosa of lower lips. The diameters of multiple ulcers were approximately $10 \mathrm{~mm}, 8 \mathrm{~mm}$, and $6 \mathrm{~mm}$ wich covered by yellowish surface (fibrinous exudate), surrounded by erythematous base and painful. Irregular erosions with the size approximately $10 \times 2 \mathrm{~mm}$ were found on the mucosa of upper lips. The rontgenographic showed the presence of resorption of the processus alveolaris and no signs of malignancy on the

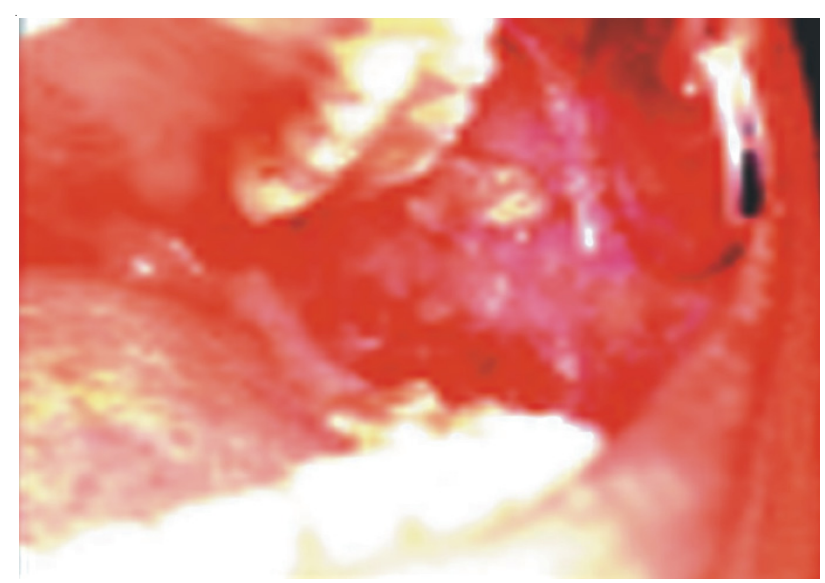

Figure 1. Multiple thick white plaques, suspected acute pseudomembrane candidosis.

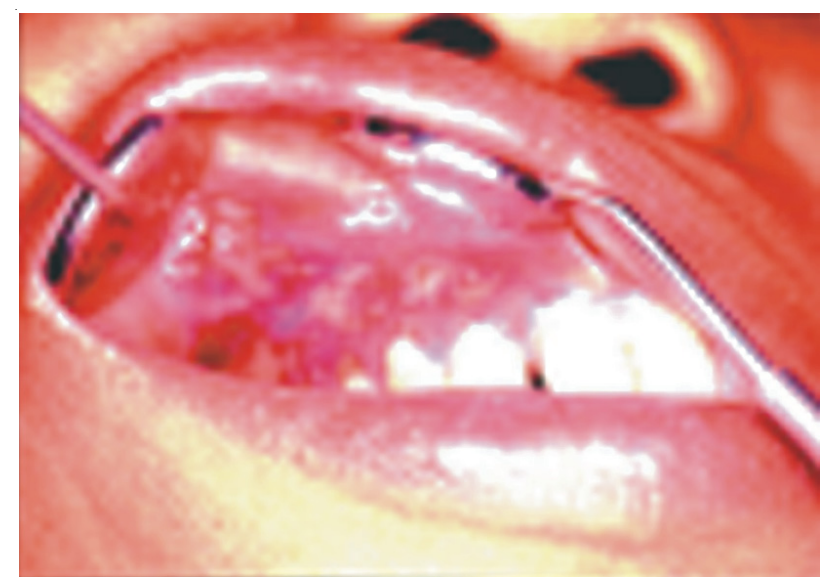

Figure 2. White irregular patch and erythematous base were found on attached gingiva of maxilla and mandibula.

left mandibula and maxilla. The lesion was suspected as thrush and candidal leukoplakia as the differential diagnose. The first treatment was $250 \mathrm{ml}$ oral rinsing containing $1.5 \%$ $\mathrm{H}_{2} \mathrm{O}_{2}$ and recalled visit on the next day.

Visit 2: On the following day, the patient could open her mouth wider than before but the symptoms and intra oral lesions still persist. The patient was referred for mycological examination and as the result a lot of yeast were found. Patient was treated with nystatin oral suspention and instructed to apply a thin layer 4 times a day after meals and at bedtime; 10 caplet of $500 \mathrm{mg}$ vitamineral (multivitamin + mineral) for 10 days and oral rinsing with $1.5 \% \mathrm{H}_{2} \mathrm{O}_{2}$.

Visit 3: According to anamnesis, three days later after the second visit, the the patient was transferred by oncologist to gynecologist and received $250 \mathrm{mg}$ etmasilat and $500 \mathrm{mg}$ tiamphenicol (antibiotic). After patient took the drugs, white patch in oral mucosa became thicker so the patient stopped to take etamsilat and tiamphenicol, and continued to use nystatin oral suspension, vitamineral and $1.5 \% \mathrm{H}_{2} \mathrm{O}_{2}$ rinse. The patient was suggested to control 3 days later. 
Visit 4: Eight days later, after had taken nystatin oral suspension, vitamineral and $1.5 \% \mathrm{H}_{2} \mathrm{O}_{2}$ rinse from Oral Medicine Department for 6 days, patient felt better. Intra oral examination showed better improvement and then treatment was repeated. Patient was suggested for recalled visit the next 7 days.

Visit 5: According to anamnesis, vaginal-biopsy was taken by a gynecologist and tiamphenicol, etamsilat, mefenamic acid, carbozokrom natrium sulfonat were given to the patient. After taking the drugs, she felt very painful in the mouth.

From intra oral examination, white patch became thicker, painful, with ulcers on buccal mucosa of 46 and on the left-mucobuccalfold, its length approximately $1 \mathrm{~cm}$. The use of medicine from the gynecologist and oral medicine's clinic were continued. The patient was then transferred to oral surgery's clinic for oral-mucosal biopsy.

\section{Visit 6 (22nd day)}

Seven days later after the fifth visit, according to anamnesis, after oral-mucosal biopsy, patient received antibiotic and anti-inflammation. Later, patient felt generally painful. On extra oral examination, right and left submandibular glands were larger, massive and painful. Intra orally, ulcers were on the left and right buccal mucosa, diameter approximately $1 \mathrm{~cm}$, surrounded erytemathous area and large white patch which could be scraped off. Attached gingival of maxilla and mandibula were diffuse, red and bright erythematous. The white patch on the right buccal mucosa was thinner than the one on the left. Clinical diagnosis suspected as acute pseudomembrane candidosis. The $1 \%$ topical gentian violet and $1.5 \% \mathrm{H}_{2} \mathrm{O}_{2}$ mouthwash were given and patient suggested for recalled 7 days later.

\section{Visit 7 (29th day)}

On the seventh visit, the patient felt better. The hystopathological features proved that the lesion was oral lichen planus (Figure 3). Intra oral examination, white patch was thinner and presented lace-like white striations on an erythematous background which unscrappable. Fiery red erythema involving attached gingival appeared on left and right gingiva, this condition called desquamative gingivitis. Yellow surface ulcer surrounded by erythematous area presented on the left buccal mucosa. A final-diagnosis was an erosive oral lichen planus disease. Triamcinolone acetonid $0.1 \%$ in ora base and mycostatin oral suspension (applied 4 times a day), vitamineral tablets were given and the patient was suggested to consume various-fruit juice. Vaginal hystopathological test showed chronic cervicitis vaginalis, so the patient was treated with Isoprenosine, Dalfarol and Noxogin vaginal tablets.

\section{Visit 8 ( $35^{\text {th }}$ day)}

The patient felt better and could eat some various diet, only slight soreness when she ate chilli. The unscrappable lace-like white striae, surrounded by erythematous area and

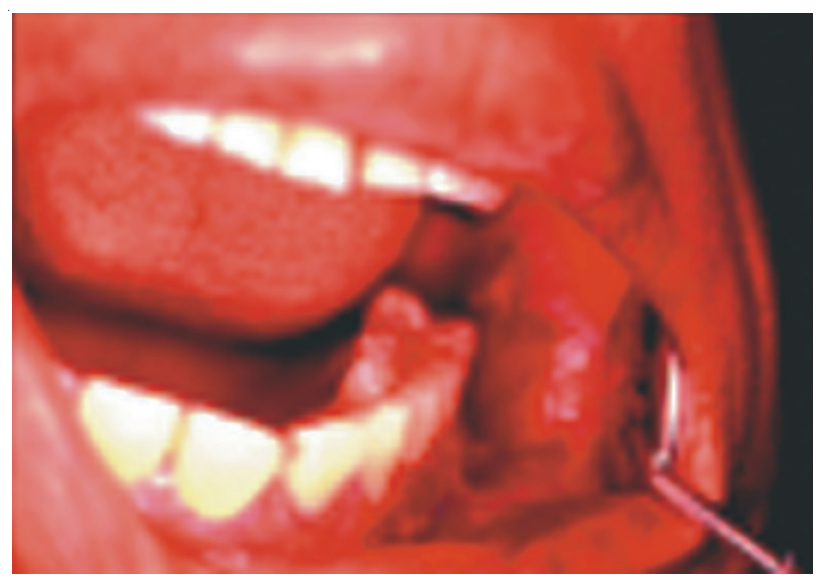

Figure 3. Lace-like white striations on an erythematous background which unscrappable.

painless was found on the left and right buccal mucosa.

Visit 9: On the third month after the eighth visit, the patient felt much improvement with normal masticatory function. Intra oral examination, erythematous area and surrounded by radier white striae showed on left and right buccal mucosa. Nystatin and $0.1 \%$ Triamcenolone acetonide were continuously applied turning 4 times a day and consumed carrot/tomato juice. The patient was referred to The Clinic of Periodontia, Oral Surgery and Conservative Dentistry for scaling, extracting the gangrene radix and teeth filling. The patient was suggested to maintain the oral hygiene. Three months later the patient did not totally recover, but the treatment reduced severity of the symptoms. The treatment was aimed primarily at reducing the duration and severity of the symptomatic outbreaks.

\section{DISCUSSION}

On the first visit, the complaint of patient was the presence of white-plaques bilateral buccal mucosa, painful, sensitive to the spicy foods and was difficult to open her mouth for one year. One month later, the severity increased. An extra oral examination showed acute lymphadenitis on the right and left submandibular gland, there was evidence of a chronic inflammation with acute exacerbation. Due to responseless to $5 \%$ sanguine extract $+0.1 \%$ polidocanol and $0.1 \%$ triamcenolone acetonide, the lesion was not only suspected chronic inflammation with acute exacerbation, but also there were other potential factors. General condition of the patient was normal, but intra orally, there were thick irregular massive, painful white plaque $10 \times 20 \mathrm{~mm}$, with erythematous mucosa which difficult to be scrapped off; on the left and right buccal mucosa. It suspected hyperkeratotic lesion or malignant lesion, and simultaneously correlated complaint of the lesion on vagina. Irregular white patch with erythematous mucosa and difficult to be wiped away, were on the left mucobuccal 
fold and attached gingiva on maxilla and mandibula. The clinical diagnosis was suspected as acute pseudomembrane candidosis with the differential diagnosis of chronic hyperplastic candidosis (candidal leukoplakia). ${ }^{8} \mathrm{H}_{2} \mathrm{O}_{2} 1.5 \%$ mouthwash and vitaminerals were given and the aim of the treatment was to avoid false negative mycological result. Aerob intra oral condition was made by giving On (O nasen) of $1.5 \% \mathrm{H}_{2} \mathrm{O}_{2}$ in order to weaken anaerob microorganism. The foam of $\mathrm{H}_{2} \mathrm{O}_{2}$ acted as an active ingredient to clean all oral debris, thus oral hygiene could be improved. Excellent oral hygiene is believed to be able to reduce severity of the symptoms. ${ }^{7}$ Vitaminerals were given to increase the immune system and to support the recovery process. While waiting for mycological result, $1.5 \% \mathrm{H}_{2} \mathrm{O}_{2}$ was given and observed the present of positive response in improving the lesions.

The following day on visit 2 , the lesions showed slight improvement, the patient could opened her mouth a little wider than before, this might be caused by $1.5 \% \mathrm{H}_{2} \mathrm{O}_{2}$. In this experiment $1.5 \% \mathrm{H}_{2} \mathrm{O}_{2}$ acted as antiseptic agent instead of antimycotic agent. Direct mycological test has shown a lot of candida hyphae type. That was evidence of candida infection even the result of mycological culture test had not known yet. Thus, 10 drops of nystatin oral suspension was applied 4 times a day after meal and bedtime and as long as possible in the mouth before swallowing.

Five days later on third visit, a lot of yeast was found in the result of the culture mycological test. Acute pseudomembranous candidosis was decided as a definitive diagnosis. On clinical examination of the intra oral showed white patch on the right buccal mucosa became thinner but there was no improvement on the other side. The lesions showed responsless to antimycotic drugs.

According to anamesis, the patient felt better after nystatin oral suspension was given. White patch in the intra oral became thinner, width of the lesions became smaller and painless. For three days the patient was referred to a gynecologist by an oncologist. Vaginal biopsy was taken and etamsilat $250 \mathrm{mg} 3$ times a day was given to stop bleeding and tiamphenikol 500mg (antibiotic) was given 3 times a day to manage the infection. Disorder recurred after the patient took both of the drugs once.

The patient stopped taking etamsilat and tiamphenicol, but nystatin oral suspension still continued. Therefore, it could be understood that responsless to antimycotic showed 5 days later due to antibiotic drug. The same episode was repeated at visit 6 ( $22^{\text {nd }}$ day), after left buccal mucosal biopsy was taken by an oral surgeon. The antibiotic treatment was assumed to be one of the predisposition factors to acute pseudomembrane candidosis. ${ }^{7}$ The commensal flora in the mouth is a stabile population, the balance of different species can be disturbed by drugs which resulted selective growth of a certain microorganism in the intra oral and followed by excessive growth of resistant organism. If it happened, C. albicans can develop to be oral candidosis. ${ }^{10}$

Acute pseudomembrane candidosis either clinically or symptomatically, will gradually improve 2-3 days after antimicotic treatment and get recovery for 10-14 days. If the lesion is persistent, there is possibility that Acute pseudomembrane candidosis simultaneously occur with other chronic mucositis such as OLP, pemphigus vulgaris or leukoplakia. ${ }^{11}$ The mucous membrane and skin are psychochemical barrier to cover the connective tissue. ${ }^{12}$ Erosion and ulceration are epithelial damage of the mucous membrane which reach basal membrane or even deeper. ${ }^{13}$ Principally, type hyphae of candida never penetrates to stratum corneum except in epithelial damage mainly chronic process as seen on OLP. ${ }^{11}$

On the fourth visit ( $8^{\text {th }}$ day) after taking antimicotic for 7 days, the patient felt much better. On intra oral examination, white plaque showed to be thinner, width of the lesion was smaller and painless, ulceration and erosion disappeared. In this case, the lesion clearly had positive response to antimycotic.

On the $5^{\text {th }}$ visit $\left(15^{\text {th }}\right.$ day) the patient had oral mucosa complaint and the pain re-occurred. On intra oral examination white patch showed to be thicker, painful with ulcer on buccal mucosa of 46 and the left-mucobuccalfold, its length approximately $1 \mathrm{~cm}$. According to anamnesis, vaginal biopsy was done and given tiamphenicol, etamsilat, mefenamat acid and carbozocrom natrium sulfonat were given. It seems clearer that the effect of antibiotic (etamsilat) to severity of oral candidosis was adequate. However, based on suspection of tissue damage under pseudomembrane of oral candidosis, histopathologycal examination was done to find out the underlying disease, such as a malignant lesion.

On visit 6 ( $22^{\text {nd }}$ day) the post biopsy area was swelling and painful, to lead difficult to open her mouth, $1 \mathrm{~cm}$ diameter of the lesion on left buccal mucosa was still found. Almost the entire buccal mucosa and attached gingival showed white patch which could be difficult scraped off, diffuse of the border and surrounded erythemathous area. The white patch on right buccal mucosa was thinner than left side, surrounded erythematous, painless and could be scrapped off. The lesion were found on the left and the right side of maxilla and mandibula. According to anamnesis, 250mg amoxillin was given by oral surgeon post biopsy. The use of antibiotic might influence the recurrency or severity of oral candidosis. So $1 \%$ gentian violet was given to prevent candida resistention to nystatin.

On visit $7^{\text {th }}$ ( $29^{\text {th }}$ day) in intra oral examination showed white plaque was thinner and presented unscrappable lace like white striations. On left and right gingival appeared a fiery red erythema covered the attached gingival, a condition called desquamative gingivitis. After candida infection decreased, clinical examination showed erosive oral lichen planus (OLP) and supported by histopathologycal examination. Thus, topical corticosteroid was given as the drug of choice on OLP and also nystatin oral suspension consecutively, because corticosteroid is predisposition factor of the occurrence of candida infection. If the result of mycological examination showed positive to $\mathrm{C}$. albicans, it is suggested to give antimicotic earlier until showed negative to C. albicans. ${ }^{4}$ 
OLP was rarely found, but the patient really suffered by the disease, mainly on erosive/ ulcerative OLP. Precise ethiopathogenesis of OLP is unknown, therefore the aim of the treatment is palliative. ${ }^{6}$ Medical treatment of OLP is essential for the management of painful, the resolution of mucosal lesions, the reduction of the risk of oral cancer and maintenance of oral hygiene. In patients with recurrent painful disease, another goal is the prolongation of their symptom-free intervals. The agent is used to treat painful of OLP (symptomatis) is topical/systemic corticosteroids. No treatment of OLP is curative. ${ }^{2,6}$

In this case, it was concluded that the triggers of oral candidosis are 1) chronic damaged/chronic inflammatory in oral mucous membrane as OLP, 2) the used of antibiotic, 3 ) the used of topical corticosteroid. If mycological examination showed positive to candidosis, it is suggested to use the antimicotic earlier than the antibiotic until mycological examination showed negative.

\section{REFERENCES}

1. Cawson RA, Odell EW. Essential of oral pathology and oral medicine. $6^{\text {th }}$ ed. Toronto: Churchill Livingstone; 2000; p. 187-93.
2. Sugerman P. Oral lichen planus. Available at: http://www.emedicine.com/derm /topic663.htm. Accessed January 10, 2002.

3. Eisenberg E. Lichen planus and oral cancer is there a connection between the two. JADA 1992 May; 123: 187-93.

4. Vinncent SD. Diagnosis and managing oral lichen planus. JADA 1991; 22: 93-96.

5. Axell T. The oral mucosa as a mirror of general health or diseases. Scand J Dent Res 1992; 100: 9-16.

6. Dorta RG, Souza JB, Oliveira DT. Ginggival erosive lichen planus: Case report. Braz Dent J 2001; 12(1): 63-66.

7. Edward PC, Kelsch R. Oral lichen planus: Clinical presentation and management. J Canadian Dental Association 2002 September; 68(8): 494-9.

8. Scully C. Candidiasis, mucosal. Copyright 2002, eMedicine.com, Inc. Accessed January 24, 2002.

9. Harijanti K. Penggunaan kortikosteroid pada perawatan OLP (Penelitian retrospektif mulai tahun 1997-2002). Tugas Akhir Pendidikan Dokter Gigi Spesialis Program studi Oral Medicine pada Fakultas Kedokteran Gigi Unair; 2003.

10. Duxburry AJ. Systemic Pharmacotherapy. In: Jones JH, Mason DK. Oral manifestation of systemic diseases. $2^{\text {nd }}$ ed. London: Bailliere Tindall; 1990. p. 443-6.

11. Allen CM. Diagnosing and managing oral candidosis. JADA 1992 January; 123: 77-82.

12. Abbas AK, Lichtma AH, Pober JS. Cellular and molleculer immunology. $1^{\text {st }}$ ed. Philadelphia: WB Saunders Co; 1991. p. 4-5.

13. Sonis ST, Fazio RC, Fang L. Principle and practice of oral medicine. $2^{\text {nd }}$ ed. Philadelphia: WB Saunders; 1995. p. 361443. 